\title{
DisClOSURE OF GAMETE DONATION IN THE UNITED STATES
}

\author{
Maya Sabatello, LLB, $\mathrm{PhD}^{*}$
}

I. HISTORICAL BACKGROUND ..................................................... 32

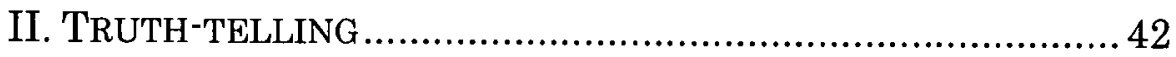

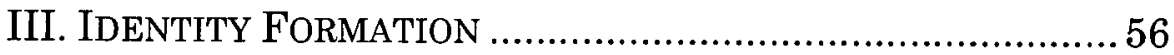

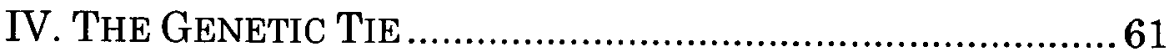

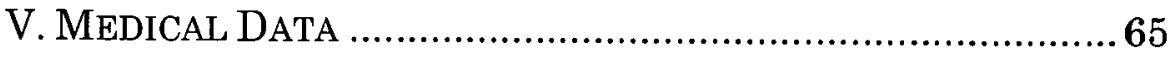

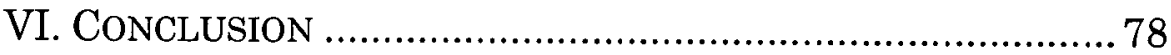

This article explores whether the United States should follow the international trend in reversing the policy of gamete donors' anonymity. Briefing the history of the practice of gamete donation, I scrutinize the four core arguments raised by disclosure proponents: the harmful effect of secrecy in the construction of family relations; the relevance of genetic information for one's identity formation; the significance of one's genetic origin to kinship; and the importance of retrieving one's genetic origin for medical reasons. I suggest that these arguments are not universal facts but mostly a matter of cultural construction of child welfare and "best interests," and that they are unfounded in existing studies based in the United States. The arguments further do not properly consider the interests of all stakeholders, including those of donor-inseminated children, nor stand the test of America's multicultural fabric, preference for non-interventionist governance, and predilection for a free market. The appropriateness of the emerging "child's right to know" and the broader implications of such a right are also considered. The article nonetheless suggests that regulating the work of fertility clinics is justified to overcome shortcomings in medical practice in the United States, especially given its unique healthcare system. 
Over the past twenty years, the once unassailable policy of preserving gamete donors' anonymity has been intensely challenged. Sweden led the way in removing sperm donors' anonymity in 1985 . Since then, Switzerland; Germany; the Netherlands; New Zealand; the Australian states of Victoria, Western Australia, and New South Wales; Iceland; and the United Kingdom have all followed suit. While some differences in the laws of these countries exist, the gist of such disclosure laws is that gamete donors are now required to provide their identifying information and to consent for the release of this information to any resulting donorconceived child, who, upon reaching maturity, may request it and approach the donor. Thus, notwithstanding the still prevalent policy of donor anonymity in many countries in the world, the trend towards disclosure of gamete donors' identifying information is visible.

Demands for the disclosure of gamete donors' identity are commonly grounded in the terminology of children's rights, especially the concepts of child welfare and "best interests" that are enshrined in the Convention on the Rights of the Child ("CRC"). 1 In the context of gamete donation, disclosure proponents underscore four main arguments: (1) the harmful effect of secrecy and preference for truth-telling in the construction of family relations; (2) the relevance of genetic information for one's identity formation; (3) the significance of one's genetic origin to kinship; and (4) the importance of genetic information for medical purposes. Subsequently, some critics have

* Postdoctoral Research Fellow at Columbia University's Center on Research of Ethical, Legal and Social Implications of Psychiatric, Neurologic and Behavioral Genetics; adjunct assistant professor at NYU's Center for Global Affairs. LLB, 1998, Hebrew University of Jerusalem; PhD in Political Science, 2006, USC; Research Fellow in Medical Ethics, 2011-2013, Harvard Medical School; Visiting Research Fellow, 2012-2013, Columbia University Law School. Previous versions and parts of this article were presented at Columbia University's Human Rights Seminar (2011), Harvard's Medical Ethics Retreat (2012), and the Hastings Center (2013), and I want to thank the participants for their useful comments.

1 Convention on the Rights of the Child, ratified Nov. 20, 1989, 1577 U.N.T.S. 3 (entered into force Sept 2, 1990) [hereinafter CRC]. 
blatantly accused non-disclosing parents of neglecting their child's best interest by selfishly putting their own rights to privacy and reproductive freedom ahead of their child's rights. ${ }^{2}$ Disclosure proponents further suggest that a child's inherent and universal two-tiered 'right to know' is recognized: a right to know about the circumstances of one's conception, and a right to know information about the donor. ${ }^{3}$

Increasingly, calls to adopt a disclosure policy are also being heard in the United States. This is the case despite the fact that assisted reproductive technologies ("ARTs") are hardly regulated in the United States, nor is the country a party to the CRC. Nevertheless, disclosure advocates justify their stance on the principles of child's welfare, best interests, and rights, all of which are well enshrined within the American legal system. While recognizing that such a change may negatively affect the number of donors, proponents argue that, "the child's right to know" prevails. ${ }^{4}$ As the debate continues and more nations adopt policies that allow for disclosure of donor information to recipient parents and children, it is important to take a closer look at the relevance of this debate to the United States.

This essay explores whether the rationales that are raised in favor of disclosure stand in the United States. After a brief history of the practice of gamete donation, I scrutinize the four core arguments raised by disclosure proponents. I argue that the implied universality of the rationales in favor of disclosure does not hold. With the exception of the point about medical data, I suggest that these arguments are matters of cultural construction rather

2 Olga van den Akker, A Review of Family Donor Constructs: Current Research and Future Directions, 12 HUMAN REPROD. UPDATE 91, 96 (2006).

3 Lucy Frith, Beneath the Rhetoric: the Role of Rights in the Practice of Non-Anonymous Gamete Donation, 15 BIOETHICS 473, 47484 (2001) [hereinafter Frith, Beneath the Rhetoric].

4 Lucy Frith, Gamete Donation and Anonymity: The Ethical and Legal Debate, 16 HuM. REPROD. 818, 818-24 (2001) [hereinafter Frith, Gamete Donation]; MIKKI MORRISSETTE, BEHIND CloseD DoORS: Moving Beyond SECRECY AND Shame (The Donor Sibling Registry, ed., 2006). 
than universal facts. The arguments may not stand the test of America's multicultural fabric, its preference for noninterventionist governance, and its predilection for a free market-characteristics that set the United States apart from European and Scandinavian countries. Moreover, I suggest that-despite the claims of child-centerednessdisclosure does not always correspond with children's best interests. Caution is needed as these arguments have been insufficiently documented in existing studies, particularly those based in the United States, and do not necessarily represent the authentic voices of donor-conceived children. The emergence of the so-called "child's right to know" should also be scrutinized; it raises profound questions about what sort of information all children, both donor and naturally conceived, have "a right to know" and what society's obligations are in ensuring that this right is exercisable-an issue that is especially challenging in light of the United States' creeds.

The argument about medical data, in contrast, has particular relevance in the United States. While this argument certainly has its own complexities, I highlight shortcomings in medical practice in the United States that are particularly harmful to the interests of donor-conceived children. Subsequently, I suggest that while secrecy among family members should remain in the realm of privacy, the interests of donor-conceived children as well as of other stakeholders can be answered by regulating fertility clinics so that they are legally required to obtain and preserve identifying information about the donor and make nonidentifying medical data available to recipient parents and to donor-conceived children at least when the latter experiences a medical condition that may be traced back to the donor. The final section summarizes the conclusions and pinpoints the need for future research.

\section{HISTORICAL BACKGROUND}

The practice of gamete donation for humans has seen dramatic changes in the past century. Three interrelated points are particularly salient. The first is the shift from 
being an esoteric practice to one that is significantly more common than had been previously imagined. Historically, the practice of gamete donation was primarily used in married couples where the husband experienced infertility, and sperm donation was used to overcome this condition. The development of in vitro fertilization ("IVF") in 1978, however, gave the practice of gamete donation a significant boost. In this process, the woman's egg is fertilized outside the woman's body and then implanted in the womb. Thus, in addition to traditional sperm donation, the practice of IVF later made possible also egg donation and embryo donation. Subsequently, towards the end of the twentieth century, gamete donation has increasingly been used not only to assist infertile husbands, but also to achieve pregnancy in couples where the wife or both husband and wife experience infertility. ${ }^{5}$ Furthermore, untraditional families, especially single mothers and same-sex couples, particularly lesbian couples, have become important consumers in this market. ${ }^{6}$ Indeed, through ART, both members of a lesbian couple can now be biologically linked to the child: one partner provides the egg, i.e. the genetic mother, while the other serves as the gestating mother.

Shifts in societal attitudes towards greater acceptance of the practice of gamete donation were further critical in this development. The highly vocal moral and religious opposition to the practice of gamete donation, ${ }^{7}$ which historically occupied much of the discourse, started to dwindle in the 1960s. Infertility has increasingly been

5 Over three million children have been born worldwide as a result of ART, with a rate of over 200,000 a year. Judith F. Daar, Accessing Reproductive Technologies: Invisible Barriers, Indelible Harms, 23 BERKELEY J. GENDER L. \& JUST. 18, 29-30 (2008).

6 Id., at 32-33; see also Julie Shapiro, $A$ Lesbian Centered Critique of "Genetic Parenthood", 9 J. GENDER RACE \& JUST. 591, 608 (2005).

7 See, e.g., Joseph G. Schenker, Legitimising Surrogacy in Israel: Religious Perspectives, in SURROGATE MOTHERHOOD: INTERNATIONAL PERSPECTIVES 243, 257-58 (Rachel Cook et al. eds., 2003); Mahdi Zahraa \& Shaniza Shafie, An Islamic Perspective on IVF and PGD, With Particular Reference to Zain Hashmi, and Other Similar Cases, 20 ARAB L. Q., 152, 162-63 (2006). 
recognized as a medical condition that can be treated and overcome. ${ }^{8} \quad$ Additionally, greater acceptance of untraditional family structures, as well as the rise in concepts of children's rights, led to the ending of the legal entanglement between gamete donation and religious opposition to the practice. Thus, while during the first half of the twentieth century courts in the United States and elsewhere viewed gamete donation as adultery and held donor-conceived children as illegitimate, in 1964, Georgia became the first state in the United States to pass a statute legitimating donor-conceived children if both husband and wife consented in writing to the donor insemination. ${ }^{9}$ Starting in the 1970s, many other states in the United States and countries around the world adopted similar laws, legalizing sperm donation and treating the husband, and not the sperm donor, as the natural father of the donorconceived child. ${ }^{10}$

Finally, the standards of medical ethics as required in the context of gamete donation have changed. Because the practice of gamete donation was historically either condemned or stigmatized, it was performed in secrecy. Donors were recruited through personal contacts and were assured anonymity and confidentiality; their records were

8 Today, it is estimated that ART technologies provide an answer for approximately $95 \%$ of infertility cases. See Miryam Z.Wahrman, Fruit of the Womb: Artificial Reproductive Technologies \& Jewish Law, 9 J. GENDER RACE \& JUST. 109, 128 (2005).

9 Sonia Fader, Sperm Banking History,, CAL. CRYobanK, http://www.cryobank.com/Learning-Center/Sperm-Banking-101/SpermBanking-History/ (last visited Oct. 27, 2013).

10 See, e.g., 1973 UNIF. PARENTAGE ACT (amended 2002). The 1973 Act was adopted by nineteen states; it was revised in 2000 and once again in 2002 to respond to the technological changes relevant to families, including DNA testing and ART. Only six states adopted the 2000 Act, and importantly, it has been criticized for not being responsive to same-sex couples who resort to ART. See generally Mary P. Byrn, From Right to Wrong: A Critique of the 2000 Uniform Parentage Act, 16 UCLA WoMEN's L.J. 163 (2007). For the United Kingdom, see the Human Fertilisation and Embryology Act, 1990, c. 37, available at http://www.legislation.gov.uk/ukpga/

1990/37/contents (last visited Oct. 27, 2013). The Act was revised in 2008. See also Elliot N. DORFF, MATTERS OF Life AND DEATH: A JEWISH APPROACH TO MODERN MEDICAL ETHICS 352 (2003). 
often not kept at all or destroyed after a time period of a few years. Recipient parents were recommended to keep it a secret, including from the donor-conceived child. The first reported instance of sperm donation at the Jefferson Medical College in Philadelphia in 1884 is an example. In that case, the physician inseminated the wife of his patient with sperm from one of his students without informing the couple about the procedure. Only once the pregnancy was achieved did the physician confide the secret to the husband, who, according to the report, was nonetheless delighted to hold the child as his own. ${ }^{11}$

Today, the regulatory environment surrounding gamete donation is markedly different. Although the privacy interests and rights of gamete donors and recipient parents are recognized and gamete donors are legally absolved from any parental responsibility, the informed consent of both donors and recipient parents is required for this medical procedure. While countries differ in their regulations of ART, there is a general consensus, especially among Western countries, that carrying out an ART service without such consent exposes an ART service provider to civil tort suits, and possibly also to criminal charges. ${ }^{12}$ In countries where gamete donation is allowed, ${ }^{13}$ recruitment

11 Fader, supra note 9.

12 Criminal liability arises in cases of battery, referring to harmful touching, including medical treatment, without the consent of the individual at stake or when the consent was obtained as a result of a lie or fraud.

13 Some countries explicitly prohibit gamete donation, e.g. Italy and Austria. In November 2011, the Grand Chamber of the European Court of Human Rights upheld the Austrian law banning egg and sperm donation other than of the spouse. According to the law, egg donation is under all circumstances prohibited, and perm donation is only possible when the sperm is directly placed in the womb of a woman, i.e. in vivo artificial insemination. The Grand Chamber ruled that although there is an increasing trend among member states towards allowing gamete donation, no clear common ground has been established as yet and that given the moral and ethical dilemmas arising from this practice, Austria must be given a wide margin of appreciation as to how to regulate this area. See S.H. v. Austria [GC], no. 57813/00, ECHR, Nov. 17, 2011, available at $\mathrm{http}: / /$ hudoc.echr.coe.int/sites/eng/pages/search.aspx?i=001107325. 
of gamete donors is often carried out in public spaces-from fertility clinics, to campuses, to on-line services. Moreover, in the United States-in contrast to most other countriesthe practice itself is viewed as part of a thriving economic market, where gamete donors are financially compensated. ${ }^{14}$ Some fertility clinics recruit egg donors by offering them lucrative sums of money per donation: whereas the average donor receives between $\$ 5,000$ $\$ 10,000$; there are reports of egg donors receiving up to $\$ 50,000$ per donation. ${ }^{15}$ Although the financial compensation for sperm donors is significantly lower, ${ }^{16}$ men often donate multiple times in multiple fertility clinics, making it a profitable practice for them as well.

The current call to reverse the policy of gamete donors' anonymity and to recognize the child's two-tiered "right to know" are grounded in those historical shifts surrounding ART practices including gamete donation. As these practices became more prevalent, some recipient parents, and, in some instances donor-conceived children, have demanded to receive more information about their donors. And while some are satisfied with non-identifying information about the donor, such as personal background and general medical data, others suggest nothing short of full identifying information so as to allow the donorconceived child to meet the donor in the future. It is this latter approach that reflects the current challenge. Although the vast majority of countries in the world still retain the policy of anonymity-in Israel and France, for

14 In the United Kingdom, Israel, and France, for instance, gamete donation has to be altruistic. Financial compensation of gamete donors is limited to expenses and inconveniences directly associated with the donation. In France, donors are only reimbursed of travel expenses. $A$ Review of the HFEA's Sperm and Egg Donation Policies - 2011, HUMAN FERTILISATION AND EMBRYOLOGY AUTH. 8, 10, (2011), http://www.hfea.gov.uk/docs/2011-01-13_Donation_review-background. pdf.

15 Usha Rengachary Smerdon, Crossing Bodies, Crossing Borders: International Surrogacy Between the United States and India, 39 CuMB. L. REV. 15, 32 (2008).

16 Id. ("Donor sperm typically costs $\$ 300$ on average with "top end" sperm going for $\$ 2,950 . ")$. 
instance, it is also explicit in law-demands for full disclosure are being made beyond the individual request and as a matter of public policy.

Reiterating the aforementioned four arguable harms, disclosure proponents ground their claims in the notions of children's rights. They commonly reference child welfare and the "best interests" stipulated in the CRC, as well as to the CRC stipulated child's rights "as far as possible, to know and be cared for by his or her parents" and "to preserve his or her identity." 17 Others suggest that in genetic-related dilemmas, the principle of "the child's right to an open future" should be applied. That is, they propose that children have some "rights-in-trust" that require adult protection so that the child can exercise those rights upon becoming an adult, and that the policies adopted should aim at maximizing the child's possible life choices. ${ }^{18}$

In response, an increasing number of countriesparticularly those in Europe and, especially, Scandinaviahave reversed the policy of anonymity and required that information about the gamete donors be recorded and, upon request, made available to the donor-conceived child. ${ }^{19}$ For the most part, these disclosure laws establish "passive registries." 20 They record some identifying information about the genetic parent, and the expectation is that the donor-conceived child, upon reaching the required age, usually between sixteen and eighteen, be the one to initiate the release of the identifying information. Thus, for instance, in Sweden, the 1985 law $^{21}$ grants a donor-

17 CRC, supra note 1 , at pt. 1 , arts. 3 I 1, pt. 1, art. 7-8.

18 DENA S. DAVIS, GENETIC DILEMMAS: REPRODUCTIVE Technologies, Parental Choices, AND Children's Future 22-34 (2001).

19 Recipient parents can receive some non-identifying information about the donor such as ethnicity, education, age, etc. as part of the ART treatment.

20 I. Glenn Cohen, Response: Rethinking Sperm-Donor Anonymity: Of Changed Selves, Non-Identity, and One-Night Stands, 100 GEO. L.J. 431, 445-47 (2012) [hereinafter Cohen, Rethinking Sperm-Donor Anonymity.

$21 \quad 5-6$ ch. Lag Om Genetisk Integritet [The Genetic Integrity Act], (Svensk författningssamling [SFS] 2006:351) (Swed.), available at http://www.smer.se/news/the-genetic-integrity-act-2006351/. 
conceived child the right to receive information about the donor's physical attributes, profession, and identifying data. Although the exact age for requesting access to the donor's information is not specified, the law stipulates that the child should be "sufficiently mature," which has been interpreted to mean "upper teens," and after the child's maturity was evaluated by an expert either at the social welfare agency or at the hospital. ${ }^{22}$

In New Zealand, the Human Assisted Reproductive Technology ("HART") Act became law in 2004. ${ }^{23}$ As of August 2005, it set up a comprehensive regime whereby information about donors, donor-conceived children, recipient parents and siblings of donor-conceived children is recorded and maintained via a national register that is organized and monitored through the Department of Internal Affairs. Donors' information includes physical attributes, ethnicity, family background and cultural affiliation, and they are required to make themselves available for contact by the donor-conceived child. ${ }^{24}$

Similarly, the 2002 law in the Netherlands ${ }^{25}$ creates a comprehensive central register, controlled by an independent national Foundation for Donor Data ("FDD") created by the government, to regulate ART and the possibilities for donor-conceived children to access information about their donors. ${ }^{26}$ It allows recipient

22 Maturity is obtained in Sweden at eighteen. Claes Gottlieb et al., Disclosure of Donor Insemination to the Child: The Impact of Swedish Legislation on Couples' Attitudes, 15 HUM. REPROD. 2052, 2052 (2000).

23 Human Assisted Reproductive Technology Act 2004 (N.Z.), available at http://www.legislation.govt.nz/act/public/2004/0092/latest/ whole.html\#DLM319306.

24 M. Legge et al., A Retrospective Study of New Zealand Case Law Involving Assisted Reproduction Technology and the Social Recognition of 'New' Family, 22 HUM. REPROD. 17, 23 (2007).

25 Act Containing Rules Relating to the Use of Gamete and Embryos [The Embryos Act], Stb. 2002, 338 (Neth.), available at http://www.minvws.nl/includes/dV/openbestand.asp?File=/images/engem bryowettekst_tcm20-107819.pdf.

26 P.M.W. Janssens et al., A New Dutch Law Regulating Provision of Identifying Information of Donors to Offspring: Background, Content and Impact, HUM. 21 REPROD. 852, 853 (2006). 
parents and donor-conceived children at or above age twelve to request access to non-identifying medical information about the donor. A donor-conceived child at or above age sixteen may also request the FDD to access identifying information about the donor. Upon receiving such a request, the FDD contacts the donor and asks permission to transfer identifying information. If, however, the donor objects, it is up to the FDD (and possibly the courts) to evaluate the donor's objections; unless there are strong counter-arguments, the request of the donor-conceived child will prevail.

In the United Kingdom, gamete donors' anonymity has been abolished since 2005. When a donor-conceived child reaches age eighteen, he or she can request the Human Fertilisation and Embryology Authority to receive information about the donor, including physical appearance, race, familial history (for instance, whether the donor was adopted or whether he or she has other children), and medical history as well as religion, occupation, interests and skills, and why the donor provided the gamete. Gamete donors are required to consent to provide their identifying information to any potential donor-conceived children at the age of legal maturity, i.e. eighteen years old. ${ }^{27}$

The new Assisted Reproductive Treatment Act ("ARTA") of 2008 in Victoria, Australia, takes this a step further. While previous law had already established a central register to record identifying and non-identifying information about gamete donors and offspring, the new Act makes it mandatory to provide identifying information to all donor-conceived children, upon request, at age eighteen. Donor-conceived children may also request such information prior to eighteen, and without the consent of the parent or guardian, so long as a counselor has found the donorconceived child to be sufficiently mature to understand the

27 The Human Fertilisation and Embryology Authority (Disclosure of Donor Information) Regulations 2004, 2004, S.I. 2004/1511 (U.K.), available at http://www.legislation.gov.uk/uksi/2004/1511/pdfs/ uksi_20041511_en.pdf. 
consequences of the information. ${ }^{28}$ Moreover, birth certificates of donor-conceived children born after January 1, 2010, have an addendum attached stating the circumstances of the child's conception and the availability of information about his or her genetic origin. ${ }^{29}$ There are currently further calls to extend this law retrospectively. ${ }^{30}$

In light of these developments, the United States presents an interesting case study to explore. Unlike most of these other countries, ${ }^{31}$ the United States lacks any comprehensive federal regulations that require fertility clinics to record information about the donors. The Food and Drug Administration ("FDA") standards are limited to health-related concerns about the gamete. While the FDA require a summary of records for semen donations and screening of donated gametes for an array of inherited and infectious diseases and conditions, there are no further obligations to keep the donor's records indefinitely or to make them available for the donor-conceived child. ${ }^{32}$ And while the American Society of Reproductive Medicine has issued recommendations to the effect that donors'

28 Assisted Reproductive Treatment Act 2008 (Vic) pt VI, s.56-61 (Austl.); Rachel Thorpe et al., In the Best Interests of the Child? Regulating Assisted Reproductive Technologies and the Well-Being of Offspring in Three Australian States, 26 INT'L J. LAW POL'Y FAMILY 259, 262 (2012); see also LAW REFORM COMMITTEE, INQUIRY INTO ACCESS BY DONOR-CONCEIVED PEOPLE TO INFORMATION ABOUT DONORS, at 19-20 (2012), available http://www.parliament.vic.gov.au/images/stories/ committees/lawrefrom/iadcpiad/DCP_Final_Report.pdf.

29 Assisted Reproductive Treatment Act 2008 (Vic) s 153 (Austl.).

30 Guido Pennings, How to Kill Gamete Donation: Retrospective Legislation and Donor Anonymity, 27 HUM. REPROD. 2881, 2881-85 (2012).

31 An exception is Australia where the issue is regulated on state rather than federal level.

32 China R. Rosas, A Necessary Compromise: Recognizing the Rights of a Donated Generation to Tame the Wild Wild West of California's Sperm Banking Industry, 37 Sw. U. L. REV. 393, 402-03 (2008); Vanessa L. Pi, Regulating Sperm Donation: Why Requiring Exposed Donation Is Not the Answer, 16 DUKE J. GENDER L. \& POL'Y 379,382 (2009). The FDA requires fertility clinics to preserve donated gamete for a period of six months and to retest them before they can be used in order to screen for infectious diseases such as HIV. 
information should be recorded and kept indefinitely, the organization's lack of legal teeth means that, ultimately, it is in the hands of the individual states to determine how to regulate the activities of private fertility clinics and gamete banks working in their region and how, if at all, to preserve gamete donors information. Consequently, although most states regulate the issue of legal parenthood when gamete donation is involved and absolve the donor from parental responsibility, less than half have regulated the operations of sperm banks, and there is inconsistency as to how, whether, and under what conditions, donors' information is obtained, is checked, and can be released. ${ }^{33}$ There are also differences in the extent of information provided about sperm and egg donors-the latter commonly requiring more ${ }^{34}$-and in price: fertility clinics charge higher rates for non-anonymous donors. ${ }^{35}$ In contrast, in July 2011, Washington became the first and only state in the United States to adopt a law requiring that gamete donors provide a medical history and identifying information to fertility clinics. ${ }^{36}$ While this law does not go as far as the law in the United Kingdom or other Scandinavian countries, it allows donor-conceived-children to access this information once they reach the age of eighteen, with the proviso that the donor can veto the provision of identifying information.

Should other states in the United States be required to follow suit and regulate gamete donation in the European and Scandinavian spirit? In the next sections I consider the four core arguments of disclosure proponents and consider their application given American social and legal characteristics and creeds.

33 Pi, supra note 32, at 384-86; Rosas, supra note 32, at 404-06.

34 The reason to the difference in information provided about sperm and egg donors may be rooted in the fact that there are more medical practices that can be performed on egg donors and given the practices of recruitment. See Andrea M. Braverman, How the Internet is Reshaping Assisted Reproduction: From Donor Offspring Registries to Direct-to-Consumer Genetic Testing, 11 MINN. J.L. SCI. \& TECH 477, 482 (2010).

35 Rosas, supra note 32 , at 415 .

36 WASH. REV. CODE $§ 26.26 .750$ (2013). 


\section{TRUTH-TELLING}

Is truth-telling always preferable over family secrecy? Disclosure proponents commonly answer "yes." Family secrets, particularly in the context of reproduction, are assumed to be "like time bombs ticking away":37 they create ongoing tensions and taint familial communication to an extent that is psychologically damaging to the child. ${ }^{38}$ Consequently, disclosure proponents argue, the child is always better off knowing the truth, earlier rather than later, and, in fact, it is the child's inherent right to have such information. ${ }^{39}$

Whether the emotional and psychological strain experienced in families where a child's genetic origin is concealed justifies disclosure is dubious, however, and caution is needed when assessing the impact of familial tension or, conversely, the beneficence of truth-telling on the child. The reality is that familial tensions exist for a variety of reasons; eliminating all family secrets is unrealistic. Furthermore, the effects of secrecy vary significantly among family members; knowing beforehand how detrimental such secrecy would be, if at all, is thus impossible. As Carol Smart stipulates, "both 'telling' and 'not telling' will have consequences and the idea that the keeping of secrets is detrimental, whereas openness is innocuous, is itself problematic." 40

Additional factors support this latter argument. First, studies have shown that some donor-conceived children raised by heterosexual couples expressed anger and frustration when disclosure occurred during the course of a

37 Carol Smart, Law and the Regulation of Family Secrets, 24 INT'L J.L. POL'Y \& FAM. 397, 399 (2010).

38 Glenn McGeel et al., Gamete Donation and AnonymityDisclosure to Children Conceived with Donor Gametes Should Not Be Optional, 16 HUM. REPROD. 2033, 2034 (2001).

39 See Vardit Ravitsky, "Knowing Where You Come From": The Rights of Donor-Conceived Individuals and the Meaning of Genetic Relatedness, 11 MINN. J.L. SCI. \& TECH. 665, 670-71, 683 (2010) [hereinafter Ravitsky, Knowing Where You Come From].

40 Smart, supra note 37 , at 400. 
traumatic event such as divorce. ${ }^{41}$ Conversely, no difference in the rates of separation or divorce between disclosing and non-disclosing parents was found. ${ }^{42}$ It is thus difficult if not impossible to know what part of a child's negative reaction can be attributed to disclosure and what part is due to the distress caused by divorce, or some similarly difficult, lifechanging event. Nor are there, to my knowledge, any studies that prove that families with donor-conceived children ("donor-conceived families") have a higher incidence of discord than non-donor-conceived-families. Why assume then that donor-conceived children adjust any less to tensions within their families than their non-donorconceived peers? Children are born into families with an array of other possible stress-factors, such as economic difficulties, ethnic discrimination, parental discord, or death of a caretaker, and they normally cope with them as a part of their life-story. Thus, it is impossible, or at least highly speculative, to distinguish between the relative harms of secrecy versus other stress-factors. Most importantly, one clearly cannot use a uniform approach to determine whether or not a specific donor-conceived child would benefit from disclosure; it has to be family- and childspecific.

Disclosure has other ramifications for recipient parents. Although Western liberal democracies have recently moved toward greater acceptance of familial pluralism, this shift is not universal. Various religious and cultural communities have remained conservative in their approach, and the stigma and social price of barrenness are high. In Orthodox Jewish and Islamic communities, for instance, a husband may be obligated by religious law or by social convention to divorce his wife on the ground of infertility, regardless of

41 Akker, supra note 2, at 96; A. McWhinnie, Should Offspring from Donated Gamete Continue to Be Denied Knowledge of Their Origins and Antecedents?, 16 HUM. REPROD. 807, 812 (2001).

42 Emma Lycett et al, Offspring Created as a Result of Donor Insemination: A Study of Family Relationships, Child Adjustment, and Disclosure, 82 FERTILITY \& STERILITY 172, 175 (2004); Susan Golombok et al, Parenting Infants Conceived by Gamete Donation, 18 J. FAM. PSYCHOL. 443, 450-51 (2004). 
whether he is actually the one who is infertile. ${ }^{43}$ A married woman who uses donated sperm may simultaneously be seen as committing infidelity and illegal sexual intercourse. ${ }^{44}$ For such couples who decide to use donated gametes anyway, a universal disclosure policy would, in effect, doom them to social isolation. Persistent inequalities between genders exacerbate the harm, and, most likely, this social isolation would be principally experienced by women.

Donor-conceived children are likewise at risk of social exclusion on religious and cultural grounds. In Orthodox Judaism, because artificial insemination of a married woman with sperm of a Jewish donor is considered adultery, a child born in such a way is classified as a bastard. ${ }^{45}$ This status, which extends also to children born out of incest relationship, holds significant implications; it bars the child from participating in and marrying within the religious community. Using non-Jewish sperm donors overcomes these religious complexities as Halakhic law defines the act of adultery to require that both parties of the illicit sexual intercourse be Jewish. ${ }^{46}$ Moreover, because the Halakhic construction of relatedness is such that a non-Jewish sperm donor is not viewed as establishing any kind of relationship with the child, "children born to different Jewish mothers from the same [non-Jewish] donor are not considered to be

43 Marcia C. Inhorn, Global Infertility and the Globalization of New Reproductive Technologies: Illustrations from Egypt, 56 SoC. SCI. \& MED. 1837, 1842, 1846 (2003).

44 Zahra \& Shafie, supra note 7 , at $162-63$.

45 SUSAN MARTHA KAHN, REPRODUCING JEWS: A CULTURAL ACCOUNT OF ASSISTED CONCEPTION IN ISRAEL 96-103 (2000) [hereinafter KAHN, REPRODUCING JEWS]. Note that Halakhic interpretations make a distinction between artificial insemination, where the sperm is introduced directly into the woman's tract and unequivocally prohibited due to the concern that it constitutes adultery, and IVF fertilization and embryo transfer for which there is no direct prohibition as it is not viewed as violating the biblical teaching that "[t]hou shalt not implant thy seed into thy neighbor's wife." Id. at 103-04 (citing Leviticus 18:20). Still, Jewish sperm donor raise some other additional religious difficulties given the prohibition on masturbation and sperm procurement for reasons other than one's fulfilling his own obligation to procreate. Id. at 94.

46 Id. at 104-05. 
related in any way" and may even marry. 47 Subsequently, the question of anonymity also differs: whereas with Jewish donors the concern of incest suggests that at least the rabbinical authorities should have access to the donor's identifying information, with respect to non-Jewish donors there is "a denial of the need to know" and anonymity of donors is upheld.48 Yet still, a non-Jewish donor does not remedy all: while such conception would not result in a bastard child or create a risk for incest, the child would still be excluded, deemed as polluting the holiness of the Jewish people and their lineage. ${ }^{49}$ Similar rejection exists also among some Muslim groups. For example, although Shi'a Muslims may allow for egg and sperm donations, the practice is still socially problematic. ${ }^{50}$ The recipient parents' endorsement of the donor-conceived child as their own does not necessarily translate into acceptance by the child's social kin and extended family of the recipient parents. ${ }^{51}$

Unique characteristics of American society play further into this debate over secrecy. Unlike its Scandinavian counterparts, the United States is an immigrant, multicultural society comprised of multiple religious and cultural communities. Its creed of non-interference in an individual's religious and cultural beliefs and practices is also particularly strong. Thus, it is not only questionable whether it is within the law's legitimate role to regulate family secrets, but demanding disclosure would also unduly impose a set of principles that are not universally shared and would unnecessarily burden infertile parents and donor-conceived children. Mandatory disclosure would virtually guarantee that members of such religious groups who want to disobey religious restrictions on gamete donation would practically be forced to leave their group, contrary to the non-interventionist spirit.

47 Id. at 105.
48 Id. at $79,165-66$.
49 Id. at $93-107 ;$ Wahrman, supra note 8 , at $131-33$.
50 Inhorn, supra note 43 , at 1847,1847 n. 4 .
$51 \quad$ Smart, supra note 37 , at 401.


The claim for universal preference of truth-telling raises two other issues. The first is that it implies that disclosure of the circumstances of one's conception-rather than the donor's identity-is needed to prevent or alleviate familial tension. This point emerges as disclosure proponents advocate, as mentioned above, for a two-tiered "right to know."52 Evidently, this construction is aimed at heterosexual couples, who, in contrast to same-sex couples or single mothers, can conceal the fact of gamete donation, particularly if the intended mother carries the pregnancy. Indeed, studies show that also in countries where the national law abolished anonymous gamete donation, heterosexual recipient parents do not disclose the donation to their child. ${ }^{53}$ But what is the scope of this new child's right to know the circumstances of his or her conception? Gamete donation would be one extreme, but should we demand from parents to disclose also parental resort to fertility medication (and its type), and information relating to IVF treatment(s)? Where do we draw the line between parental privacy and the child's right to know? The prevalence of the practice of ART does not mean that parents necessarily want to share such experience with others, including their children. The situation is further complicated by practical policy issues. Given that gamete donors' records may have been destroyed, a requirement of disclosure may result in the donor-conceived child experiencing strong frustration and anger towards the recipient parents with no remedy available to either of them to resolve the tension. Thus, even if open and candid relationships between parents and children are preferable, ${ }^{54}$ it is questionable whether the benefit of knowing the circumstances of one's conception when, practically

52 Frith, Beneath the Rhetoric, supra note 3, at 473.

53 Akker, supra note 2, at 96.

54 The Practice Comm. of the Am. Soc'y for Reprod. Med. \& the Practice Comm. of the Soc'y for Assisted Reprod. Tech., Am. Soc'y for Reprod. Med. and Soc'y for Assisted Reprod. Tech., Recommendations for Gamete and Embryo Donation: A Committee Opinion, 99 FERTILITY AND STERILITY 47 (2013) (most recent recommendations of disclosure by the ASRM). 
speaking, further information about the donor may not be available, outweighs the harm of not knowing at all.

The second issue revolves around the question of, if disclosure of gamete donation is indeed paramount, what sort of responsibility do we as a society owe donor-conceived children to ensure that they know the truth. This is especially so if access to a donor's information is conceptualized as a legal, rather than a moral, right. Indeed, one of the most important aspects of a right is that the bearer of rights can exercise it independently. But in the context of gamete donation, the terminology of rights is elusive. As the overwhelming majority of donor-conceived children born to heterosexual couples-including those born in countries that reversed the policy of anonymity-are not told about the circumstances of their conception, ${ }^{55}$ the child's right is practically subjected in its entirety to the discretion of others. Thus, if truth-telling in family relations is deemed vital as a societal value and as a right, "active registries" seem to be the ideal solution. ${ }^{56}$ In the case of active registries, the burden would be on the registry to contact the children once they have reached a certain agreed-upon age to inform them about their genetic origins and provide them with an opportunity to learn about the identity of their genetic parents or parents. ${ }^{57}$ Alternatively, the law could require, for instance, that birth certificates include an addendum stipulating the child's circumstances of conception, as has been adopted in Victoria, Australia, and considered in the United Kingdom and in New South Wales, Australia. ${ }^{58}$

$55 \quad$ Akker, supra note 2, at 96.

56 Cohen, Rethinking Sperm-Donor Anonymity, supra note 20, at 445-47.

$57 \quad I d$.

58 Victorian Assisted Reproductive Treatment Act 2008, (Vic) s 153 (Austl.); Eric Blyth et al., The Role of Birth Certificates in Relation to Access to Biographical and Genetic History in Donor Conception, 17 INT'L J. ChILD. RTS. 207 (2009); Patrick Lion, Sperm Donors' Secret Details Tagged on Birth Certificates, The DaIly TelegrapH (Feb. 17, $2012 ; 12: 00$ AM), http://www.dailytelegraph.com.au/archive/national$\mathrm{old} /$ sperm-donors-secret-details-tagged-on-birth-certificates/storye- 
Undoubtedly, such active registries would harmonize the child's right to know and the preference for truth-telling in family relations. But for a legal right to know, active registries are still insufficient. Children conceived to mothers after occasional or multiple-partner sexual intercourse may not know their genetic father. ${ }^{59}$ Other presumed father-child relationships may turn out to be false. Physicians facing cases of "misattributed paternity," where the familial relationship is unintentionally refuted during medical diagnosis and treatment, do not necessarily disclose such sensitive information. 60 Moreover, studies have shown that among traditional heterosexual families, a marked number of fathers-in the United States this is estimated at ten percent ${ }^{61}$; in the United Kingdom it is one

6freuzr-1226273279109; see also Ravitsky, Knowing Where You Come From, 681-2.

59 Cohen, Rethinking Sperm-Donor Anonymity, supra note 20, at 443.

60 Kenneth Prager, Professor of Clinical Med. and Chair of the NYP Ethics Comm., Address at the Gold Foundation Ethics for Lunch Series: Ethics for Lunch: Misattributed Paternity (Nov. 30, 2010); see also Cohen, Rethinking Sperm-Donor Anonymity, supra note 20, at 44345 (raising a similar point).

61 Jane Alfred, Flagging Non-Paternity, 3 NATURE REV. GENETICS 161 (2002). It is difficult to know whether this rate is accurate. Media reports and organizations dedicated to revealing "paternity fraud" claim that the rate is as low as $14 \%$ and up to as high as $30 \%$. Paternity Fraud Rampant in the U.S., WND (Feb. 18, 2006), http://www.wnd.com/2006/02/34861/ (last visited Nov. 13, 2013); see also, PATERnITY FRAUD CTR., www.paternityfraud.com. Conversely, the American Association of Blood Bank, the only organization in the United States to collect information about relationship genetic testing from approved laboratories, suggests in its 2010 annual report, the latest available, that the average exclusion rate of paternal relationships is $20.44 \%$ with a standard deviation of 6.62 . However, this percentage includes testing following a mother's request to determine who among a few possible men is the father or when the recognized man raises a question of infidelity after which a few other possible men are tested, leading the organization to conclude that "[t]here is no evidence that a large number of the men excluded in the testing were misled into believing they are the biological father of a given child." Annual Report Summary for Testing in 2010, AABB 4, http://www.aabb.org/sa/ facilities/Documents/rtannrpt10.pdf; see also Sally Macintyre \& Anne Sooman, Non-Paternity and Prenatal Genetic Screening, 338 LANCET 
out of seven fathers-may unknowingly raise children that are genetically unrelated to them. ${ }^{62}$ Should a disclosure policy apply to those children as well? If the child's right to know should necessarily prevail, naturally-conceived children should not have any less of a right to know about their genetic origins. It further follows that society at every level, from government agencies to medical professionals who perform the procedure down to the individual, must take appropriate measures to ensure that this right can be exercised.

The possibility of such an active registry, or its alternative in the form of birth certificate addendum, is further problematic in the United States context. First, it is doubtful that such an option would withstand the test of privacy law in medical practice or family relations. With regard to the first, the physician-patient relationship generally enjoys the privilege of confidentiality. While it has been suggested that this privacy can be revoked in the context of lethal infectious diseases, for instance, informing the intimate partner of a person who is an HIV/ AIDS carrier, the general consensus is that it is the patient who should be warned about the risks and encouraged to act upon that risk by warning others. ${ }^{63}$ A similar approach has been taken with regard to the diagnosis of genetic disorders among family members. ${ }^{64}$ While the possibility that a

869 (1991); Kermyt G. Anderson, How Well Does Paternity Confidence Match Actual Paternity?, 47 CURR. ANTHROPOLOGY 511, 513 (2006).

62 McWhinnie, supra note 41, at 814 ; see also Cohen, Rethinking Sperm-Donor Anonymity, supra note 20, at 443-45 (raising a similar point).

63 See generally Laura Lin \& Bryan A. Liang, HIV and Health Law: Striking the Balance between Legal Mandates and Medical Ethics, 7 VIRTUAL MENTOR, Oct. 2005, http://virtualmentor.amaassn.org/2005/10/pdf/hlaw1-0510.pdf, but see Tarasoff v. Regents of the Univ. of Cal., 551 P.2d 334 (Cal. 1976) (establishing the legal duty of psychotherapist to warn a third party of foreseeable harm where there was a clearly identified victim).

64 See Pate v. Threlkel, 661 So. 2d 278 (Fla. 1995) ("Our holding should not be read to require the physician to warn the patient's children of the disease. In most instances the physician is prohibited from disclosing the patient's medical condition to others except with the patient's permission. . . . Moreover, the patient ordinarily can be 
physician may have a broader duty to take reasonable steps to warn those likely to be affected has been raised, ${ }^{65}$ in both legal and bioethics scholarship and practice the first interpretation has prevailed.66 A requirement that the professionals who carried out donor-insemination would have an obligation to report identified patients seeking $\mathrm{ART}^{67}$ to other third parties, including national- or statelevel agencies, in the absence of health risk would thus require a major revolution in medical practice in the United States.

This issue is further complicated by considerations of privacy in family relations. The family institution in the United States is commonly awarded significant leverage in its internal affairs; it is seen as almost sacred from public intervention. However, in the lack of a national or

expected to pass on the warning. To require the physician to seek out and warn various members of the patient's family would often be difficult or impractical and would place too heavy a burden upon the physician. Thus, we emphasize that in any circumstances in which the physician has a duty to warn of a genetically transferable disease, that duty will be satisfied by warning the patient.").

65 Safer v. Estate of Pack $\square, 677$ A.2d 1188 (N.J. Super. Ct. App. Div. 1996); see also Molloy v. Meier, 679 N.W.2d 711, 719 (Minn. 2004) (holding that "a physician's duty regarding genetic testing and diagnosis extends beyond the patient to biological parents who foreseeably may be harmed by a breach of that duty."). The specific circumstances of the case are important to note. The physicians were negligent primarily because they did not follow the standard of care of testing for Fragile X disorder although they suspected it to be the case and the child clearly exhibited associated developmental delays. Molloy, 679 N.W.2d at 716 . There is a high probability of genetically transmitting this disorder and a reliable, acceptable and widely available test for it; and further worse, the physicians gave the biological mother the impression that they have tested the child for this genetic disorder and that it was negative whereas in fact, the test was not performed. Id. at 719 .

66 Faith Lagay, A Physician's Role in Informing Family Members of Genetic Risk, 7 VIRTUAL MENTOR, June 2005, http://virtualmentor.ama-assn.org/2005/06/pdf/hlaw1-0506.pdf.

67 I distinguish here between reporting on number of (nonidentified) patients who receive treatment and the subsequent number of successful (or unsuccessful) conceptions and births, which may be required for statistic purposes and are legitimate to require, and the provision of identifying information about patients (who received treatment). My concern refers to the latter. 
comprehensive state-level registry of donor-conceived children in the United States, and if indeed all children have a right to know their genetic origin, the only alternative for the aforementioned active registry or the birth certificate addendum would be to issue birth certificates only once the newborn is tested for genetic compatibility with the putative parents. If the genetic match fails, a note to this affect would be recorded on the child's birth certificate. Surely such a measure is highly intrusive to a family's privacy and contrary to American creeds. Moreover, while the state has the responsibility of parens patriae to protect its young citizens, also at the cost of familial privacy, this responsibility is generally activated only once the familial environment has failed. It is a measure of last resort, not first. Thus, for instance, courts generally support interfering with parental rights and prerogatives only when the child's physical health or safety is in serious danger. ${ }^{68}$ Conversely, when the family is functioning well and the children are age-appropriately developed, the legal parents exercise discretion over how they raise their children and what values they pursue. With no further data about the harmful effects of the secrecy of gamete donation and whether they amount to forms of child neglect and abuse that justify intervention, ${ }^{69}$ establishing an active registry and its alternatives, as would logically be required for a donor-conceived child's legal right to know, may thus be an inappropriate use of governmental power.

68 See, e.g., Lori G. Beaman, Religion and Rights: the Illusion of Freedom and the Reality of Control, 6 CULTURE \& RELIGION 17-29 (2005) (discussing the case of Bethany Hughes, a minor and a Jehovah's Witness member who refused a blood transfusion for cancer treatments.) The court in that case dismissed her argument that she should not be forced to receive the treatment on the basis of her right to religious freedom. Alberta (Director of Child Welfare) v. B.H., [2002] 6 Alta. L.R. 4th 34, 11 W.W.R. 752 (Can. Alta. Q.B.). See also, e.g., Jehovah's Witness v. King Cnty. Hosp., 278 F. Supp. 488 (W.D. Wash. 1967), aff'd, 390 U.S. 598 (1968).

69 Maya Sabatello, Are the Kids Alright? A Child-Centred Approach to Assisted Reproductive Technologies, 31 NETH. Q. OF HUM. RTS. 74, 81-87 (2013) (discussing ART as a form of child's neglect and abuse). 
Second, the relatively conservative definitions of "family" in the United States, as compared to other Western countries, should be borne in mind. As scholars studying the United States judicial system have observed, in cases concerning ART-related disputes courts tend to accept the claimant whose familial structure follows the traditional heterosexual one of "one female mother, one male father (both married to each other)."70 Furthermore, although some changes in the judicial understanding of family relations, in light of ART, have certainly occurred, ${ }^{71}$ the inclination towards a traditional family structure comprised of only two parents, whether heterosexual or same-sex couples, remained; indeed, this two-parents-only family structure is almost exclusively endorsed also in parentage laws and courts' decisions in the United States. ${ }^{72}$ This is significantly different from the situation in many other Western countries where there has been an increasing legal acceptance of the pluralism of family structures and combinations of family relations, from same-sex couples to cohabiting heterosexual partners to recognition of three

70 JANET L. DOLGIN, DEFINING THE FAMILY: LAW TECHNOLOGY AND REPRODUCTION IN AN UNEASY AGE (1997), cited in Legge et al., supra note 24, at 18; see also Melanie B. Jacobs, Why Just Two? Disaggregating Traditional Parental Rights and Responsibilities to Recognize Multiple Parents, J.L. \& FAM. STUD. (forthcoming), available at http://papers.ssrn.com/sol3/papers.cfm?abstract_id=1012333.

71 Janet L. Dolgin, The Fractionalization of 'Parent': Transformations in Society and the Law, 5 EXPERT REV. OBSTETRICS \& GYNECOLOGY 665 (2010).

72 Diane M. Goodman, Why Can't Children Have Three Parents?, L.A. LAW, Dec. 2011, at 36 (2011-2012) [hereinafter Goodman, Why Can't Children]. See also, e.g., McDonald v McDonald, 608 N.Y.S.2d 477 (1994) (dismissing the ex-husband challenge of the wife's legal parentage as she used egg donation to conceive); Johnson v Calvert, 851 P.2d 776 (Cal. 1993) (granting the legal parentage to the intended and genetic mother in a case of gestational surrogate, where the surrogate has no genetic tie to the child). More recent cases also determined that two mothers in a same-sex relationship could both be registered as the legal parents. See, e.g., K.M. v. E.G., 117 P.3d 673 (Cal. 2005) (revolving around a genetic and gestational mothers); Elisa B. v. Super. Ct., 117 P.3d 660 (Cal. 2005) (finding that the two mothers were the legal parents); In re Parentage of Robinson, 890 A.2d 1036 (N.J. Super. Ct. Ch. Div. 2005). 
legal parents. ${ }^{73}$ Thus, whereas in Victoria, Australia, and New Zealand, ${ }^{74}$ for instance, a requirement for registration

73 The Netherlands, Belgium, Spain, Norway, Portugal, Iceland, Sweden, Denmark, and Canada have all adopted laws recognizing samesex marriages. Other countries that recognize civil unions of both same sex couples and unmarried heterosexual couples on the national level include the United Kingdom, New Zealand and Germany. Additionally, Israel, France and Japan recognize same sex marriages performed in other countries. In the United States, in contrast, the law lags behind. In the aftermath of the Supreme Court's decision in United States $v$. Windsor, 133 S. Ct. 2675 (2013), the Obama Administration has decided to reconsider the status of same-sex couples for immigration and Federal tax purposes. However, recognition of same-sex marriages is not nationally required but dependent on the individual states, and currently, most of the states still do not recognize same-sex marriage. Further, in stark difference from other Western and European countries, cohabitant heterosexual relationship are not recognized as a matter of federal policy for issues such as immigration, taxation, and healthcare benefits. David Masci et al., Gay Marriage Around the World, PEW RES. CTR. (July 9, 2009), http://www.pewforum.org/Gay-Marriage-and-

Homosexuality/Gay-Marriage-Around-the-World.aspx; Gay Marriage Legalities Worldwide, GAY WEDDING DESTINATIONS, http://www.gayweddingdestinations.com/information/gay-marriagelegalities-worldwide.aspx (last visited Nov. 15, 2013). For multi-parents structures, see, e.g., R.A. and G.D. v. Family of Bereaved Benefits Officer delivered by the Israeli Rishon Lezion Magistrate Court (application 41988-03-11), delivered February 3, 2013 (recognizing the deceased lesbian partner as the surrogate parent of the child, in addition to the child's biological father and mother.) See also Susan Donaldson James, My Three Daddies: California Eyes Multiple Parenting Law, ABC NEwS, July 3, 2012, http://abcnews.go.com/Health/ GMAHealth/california-considers-bill-multiple-legal-parents/story?id= 16705628.

74 Legge et al., supra note 24, at 22-23. See in this regard also the order of District Court in New South Wales, Australia, that the sperm donor is removed from the birth certificate of his daughter with whom he had maintained a relationships and financial support since birth, given the right of the birth mother's former partner to be named on the register. As the law allows for the registration of only two parents, the court ruled in favor of the two mothers, while also suggesting that that "the law should be rethought to allow for three parents to be listed on a birth certificate" given "the inadequacy of laws dealing with multiparent families." Oliver Timmis, Lesbian Couple Have Sperm Donor Removed from Birth Certificate, BIONEWS, August 22, 2011, http://www.bionews.org.uk/page_104979.asp; AA v Registrar of Births 
of genetic ties on the birth certificate may simply feed into the societal acceptance of the diversity of non-traditional family structures, in the United States it is likely to yield the opposite result. Given previous experience, and unless measures are simultaneously taken to broaden the legal acceptance of non-traditional families and the possibility of a "multiparent model" that includes more than two parents, a requirement of registration of donor conception on the birth certificate runs the risk that it would merely exacerbate the stigmatization of such non-heterosexual and non-genetic families and donor-conceived children rather than further their welfare and best interests. In a parenthood dispute between a lesbian couple and sperm donor, for instance, the donor might prevail over lesbian couple simply because of the judicial perception that the same-sex parents do not form an intact family, or because of a conservative belief that a father is essential for the child's well being. ${ }^{75}$

Finally, adopting an active registry in the United States is problematic also given the phenomenon of reproductive tourism, where individuals and couples travel to receive medical treatment in countries other than their own. Although exact data on the scope of the phenomenon in the United States in unavailable, there is no doubt that the United States is an active player in this market. As most industrialized countries prohibit the commercialization of gamete donation, especially egg donation, as well as of other

Deaths and Marriages [2011] NSWDC 100, (Austl.), available at http://www.caselaw.nsw.gov.au/action/PJUDG?jgmtid=154026.

75 Goodman, supra note 72, at 36; see also Jhordan C. v. Mary K., 224 Cal. Rptr. 530 (App. 1986) (accepting legal paternity suit of a known sperm donor who established relationship with the child and recognizing the biological mother's partner as de facto parent with visitation rights); but see Jacob v. Shultz-Jacob, 923 A.2d 473 (Pa. Super. Ct. 2007) (determining that a child may have three parents where a former lesbian couple and the sperm donor who established relationship with the resulting children were all held as having some parental duties and rights). Note that in those cases the sperm donor was known, the medical procedure was not undertaken by a physician, and while the parties disagreed as to their arrangements for future relationship with the child, in practice, the genetic father had already established such relationship with the child. 
ART-related services (including surrogacy and in some countries gamete donation ${ }^{76}$ ), the United States has turned into a leading international destination for couples and individuals from other countries. ${ }^{77}$ Should the United States extend its hands to donor-conceived children born to foreigners who come to the United States for gamete donation, sometimes in contravention of their own national laws?78 If the child's right to know is universal, as argued, the answer to this question should be positive. This however would significantly hamper the lucrative multibillion per year business in the United States, ${ }^{79}$ while also contravening principles of states' jurisdiction and creating a real challenge to the law's implementation. Moreover, the chances are that recipient parents, both foreign coming to the United States and Americans who want to circumvent the active registry, will not give up their desire for privacy in establishing a partially biologically related family and will instead travel to other locations to purchase gametes and ART services, often without governmental supervision, while others will turn to the black market. Both scenarios hold significant health risks to the recipients, the donors, particularly egg donors, and the future donor-conceived child. Importantly, these scenarios will also yet again undermine the law's purpose of ensuring that the right of a donor-conceived child to know is upheld.

76 See S.H. v. Austria [GC], no. 57813/00, ECHR, Nov. 17, 2011, available at $\mathrm{http} / / /$ hudoc.echr.coe.int/sites/eng/pages/search.aspx?i=001107325.

77 Smerdon, supra note 15 , at $21-22$.

78 Egg and sperm donation for IVF are banned in Austria and Italy; Germany and Norway allow sperm donation but ban egg donation. Maria Cheng, Strict Fertility Treatment Bans in Europe Draw Criticism, US TODAY NEwS, Mar. 4, 2012, http://usatoday30.usatoday.com/news/health/story/2012-04-13/Europefertility-bans-limits/54250984/1.

79 Hundreds of sperm banks, egg banks, private and independent clinics, surrogacy agencies, and other related services were established in the past few decades around the world and generate billions of dollars per year. Michael J. Malinowski, Creating Life, Examining the Legal, Ethical, and Medical Issues of Assisted Reproductive Technologies: $A$ Law-Policy Proposal to Know Where Babies Come From During the Reproduction Revolution, 9 J. GENDER RACE \& JUST. 549 (2006). 
Truth-telling is an important, but not absolute, value. This is especially so in the context of reproduction and gamete donation: the possibility of disclosure has to be balanced with the potentially serious repercussions on the recipient parents, donors, and donor-conceived children that may occur. These repercussions necessitate a clear line between disclosure and inappropriate interference in one's privacy that is not easy to draw. Importantly, if truthtelling is the paramount value and a legal right, it should apply to all children, whether conceived naturally or through gamete donation, and would require that we, as a society, consider what measures we are willing to adopt to ensure that the truth is, under all circumstances, being told. Such discussions also require that we rethink how family is conceptualized in the United States. Moving toward a greater legal and social acceptance of the diversity of nontraditional and non-genetically related familial structures and combinations is certainly more reflective of reality, and, thus, is critically important for families and children who are raised in such familial structures. But making a legal change only in the context of disclosure of gamete donation without a concomitant to broader social changes that accept non-traditional and multiparent families invites backlash especially for donor-conceived-families and the children themselves that are involved.

\section{IDENTITY FORMATION}

Disclosure proponents raise another argument: the importance of information about genetic origin for the child's identity formation. As Vardit Ravitski explains, "The development of personal identity requires understanding 'where you came from' . . . it means knowing what the donor is like in ways that would help offspring understand why they are the way they are." 80

Commonly, an analogy is drawn from adoptees, where studies have shown the devastating impact their abandonment and the lack of information about their

80 Ravitsky, Knowing Where You Come From, 665, 674. 
genetic parents have had on their identity development and sense of worth and belonging. ${ }^{81}$ Disclosure proponents similarly suggest that donor-conceived children face "genealogical bewilderment," poor self-perception and identity crises, and a sense of being an outsider among the family in which he or she is raised. 82 They subsequently insist that a disclosure policy, akin to the one currently in place with adoptees, should be implemented.

These suppositions are problematic. The argument about the indispensability of knowing one's genetic origin insinuates that genetics is equated with identity. While certain characteristics are influenced by one's genes (e.g., temperament and appearance), such an understanding of identity overemphasizes genetic composition and underestimates other facets of identity. As the feminist movement and, subsequently, the disability rights movement have so fervently emphasized, identity formation is about more than genetics. Significantly, one's web of relations is paramount. This is particularly so with regard to children. Contrary to the essentialist-genetic notion of identity, studies show that children's identity is fluid; pluralistic; and dependent on their social and familial relationships and ethnic, religious, and cultural backgrounds. ${ }^{83}$ This diversity is especially pertinent. Unlike in Western liberal culture, some religious and cultural groups residing in the United States do not hold genetics as establishing any relatedness with the resulting child, especially with respect to the genetic father. ${ }^{84}$ It is thus hard to imagine that members belonging to such groups would nonetheless find knowing one's genetics origin as essential for one's identity formation.

81 Frith, Beneath the Rhetoric, supra note 3, at 479-80.

82 Akker, supra note 2, at 96; McWhinnie, supra note 41 , at 814 ; Michelle Dennison, Revealing Your Sources: The Case for NonAnonymous Gamete Donation, 21 J.L. \& HEALTH 1, 16-17 (2007).

83 Maya Sabatello, Children's Bioethics: The INTERNationaL Biopolitical Discourse on HaRMFUl TRAditional PRACTICES AND THE RIGHT OF THE CHILD TO CULTURAL IDENTITY 215-20 (2009) [hereinafter SABATEllo, Children's Bioethics].

84 See discussion supra Part I (discussing Orthodox Judaism); see also discussion infra Part III. 
Whether donor-conceived children's process of identity formation differs from that of naturally conceived children is hard to assess. Instances of identity crisis have been reported with respect to donor-conceived children raised by same-sex or single-parent families, where the absence of a genetic parent is obvious and no information about the donor is available, or in heterosexual families when disclosures occurred in traumatic circumstances. Further, most studies conducted are biased as samples were taken from online registries for recipient parents or donorconceived siblings, who clearly are already invested in learning about their genetic parent. Conversely, no studies have established a prevalence of identity crises among the millions of existing donor-conceived children-particularly among those who do not know-and whether it is beyond what all children experience as they mature. And considering that gamete donation commonly remains a secret from the closest family members, including the donor-conceived child, there is little evidence to suppose that the price of anonymity to the donor-conceived child's identity development is as severe as is argued by disclosure advocates. Requiring disclosure may thus catalyze invasive interventions in families that are actually thriving with well-developed and satisfied children. Before the concomitant policy change is implemented, further studies are needed to determine the correlation of identity development to disclosure and non-disclosure among donorconceived children.

For this reason, comparing donor-conceived children to adopted children is inapt: whereas adoptees were, for whatever reason, abandoned by their genetic parents, donor-conceived-children were intended and desired all along. Adoptees' anger and frustration may also be influenced by their memories, even if vague, as they may have experienced or witnessed traumatic events that led to their adoption (e.g., child abuse), experiences that donorconceived children do not share. Concluding, without appropriate studies, that donor-conceived children necessarily share the complex identities of adoptees is thus 
erroneous and presumes identity crises where they may not exist.

This information-translated-into-identity debate must confront another privacy matter: How much information about one's donor would be required to satisfy the donorconceived-child's sense of identity? Besides donors' medical data, recipient parents have begun requesting other details such as childhood and adult pictures and in-depth psychosocial histories, such as a donor's earliest memory; favorite book and movie or other hobbies; whether a donor prefers certain weather; and the ways in which a donor shows his or her love.85 Such requests suggest that this information is somehow tied with genetic traits or that it is otherwise important to personalize the donor ${ }^{86}$ and thus important to enable the donor-conceived child's to develop his or her identity.

This latter suggestion, which is at the heart of the information-translated-into-identity debate, is problematic on a few levels, however. If knowing about one's genetic origin and the characteristics of the donor is so crucial to one's identity, making it a legal obligation from donor to provide such information is justified. But what are the limits? For instance, whether the legal requirement of providing other information such as the donor's sexual behavior and other personal crises should be considered. Such information is deeply personal and should be protected as a matter of privacy. Simultaneously, the factual basis on which this suggestion rests is tenuous at best. Not only that, it is not at all clear what is the connection between genetics and such characteristics-for instance, whether weather preference has anything to do with genetics-but it also assumes that there is one "real" identity that the donor-conceived child will develop once the information about the donor is provided. This however is not the case: studies on children's identity have established that children

85 Braverman, supra note 34 , at $485,492$. 
have their own identities that differ from the identities of their parents. ${ }^{87}$

Concurrently, a further question arises: can information rather than an actual relationship ever be enough? Indeed, in other countries that made the provision of personal information such as a family tree and whether the donor was adopted a requirement, such as has been the case in New Zealand and Victoria, Australia, the donor-conceived child also has the right to contact the donor and establish an actual relationship with him or her. Yet again, in the United States context, this would require a real revolution in the understandings of families, which is unlikely to be endorsed by American society any time soon. It would also require that donors reconceptualize their donation to mean familial relationship rather than an economic transaction; 88 however, this, too, would be difficult to achieve. Studies show that in countries that adopted a disclosure policy, the number of gamete donors dropped significantly. ${ }^{89}$ Subsequently, long waiting lists now exist for couples and individuals who resort to gamete donation, whereas those who can afford it travel to the United States and to other destinations where donors' anonymity is upheld. ${ }^{90}$ Thus,

87 Judith Ackroyd \& Andrew Pilkington, Childhood and the Construction of Ethnic Identities in a Global Age, 6 Childhood 445 (1999); see also SABATELLO, CHILDREN'S BIOETHICS, supra note 83, at 177-82 (discussing the complexities of children's identities).

88 See discussion infra Part III.

89 Frith, Gamete Donation, supra note 4, at 822-23. Note that the permanency of this decline has been disputed; however, there is no doubt that the immediate result is greater limitations on the possibilities of recipient parents to create a family and on the ability of fertility clinics, a strong lobby in the United States, to provide services. See I. Glenn Cohen, The Right Not to Be a Genetic Parent?, 81 S. CAL. L. REV. 1115 (2008) (arguing for a right not to be a genetic parent because of the harm caused by what he terms "attributional parenthood"; that is, the fact that society assigns the status of parent to the provider of genetic material also when the legal system absolves the genetic parent from any parental responsibility).

90 In the Netherlands, for instance, the waiting list for sperm donation stands on two years; in the United Kingdom recipient parents may wait three to five years for egg donor. New Law Affects Sperm Donation in the Netherlands, BIoNews, June 4, 2004, 
while providing extensive information, and allowing for actual relationships, can be optional, making it obligatory necessitates consideration as to what constitutes a reasonable expectation for information and what the broader implications of such a change are.

The issues highlighted here are not intended to dismiss or undermine the feelings of frustration or identity crises expressed by donor-conceived children who know about their conception story but have no recourse, as the information about the gamete donor is unavailable. Indeed, recipient parents should take seriously these feelings, especially when gamete donation is obvious or when recipient parents intend all along to tell the child about the circumstances of his or her conception. Rather, what this discussion intends to show is that the identity-formation claim is not as absolute or straightforward as suggested by disclosure proponents. It is socially constructed --a point that is further strengthened given that the calls for disclosure do not necessarily represent all recipient parents and their donor-conceived children, and given the number of children unknowingly raised by a biologically unrelated parent whom are seemingly well-developed. More studies about the identity development of donor-conceived children are thus essential before changes in the law are adopted so to ensure that they resonate with children's needs.

\section{THE GENETIC TIE}

A third argument that disclosure proponents raise is that genetic ties create an intrinsic emotional attachment; a donor-conceived child, it is so argued, then has a right that this connection be realized through the provision of disclosing identifying information. ${ }^{91}$ Others have suggested that this right should include access to the donor's full

http://www.bionews.org.uk/page_11973.asp; $A$ Review of the HFEA's Sperm and Egg Donation Policies - 2011, supra note 14, at 3.

91 Eric Blyth, To Be or Not to Be? A Critical Appraisal of the Welfare of Children Conceived through New Reproductive Technologies, 16 INT'L J. CHILD. RTS. 513 (2008); McWhinnie, supra note 41, at 815. 
identity to enable the donor-conceived child to develop a relationship with the genetic parent. ${ }^{92}$

Contrary to this assumption, research has shown that the genetic tie is largely a social construct that is not universally upheld. Among African Americans, for instance, the notion of the family is often politically, and not genetically, constructed. It is a matter of sisterhood and brotherhood in one's political environment. ${ }^{93}$ Similarly, for religious rationales, Orthodox Judaism does not hold nonJewish genetic fathers as establishing any paternal relatedness with a child born to a Jewish woman. ${ }^{94}$ Likewise, among indigenous groups such as the Navajo nation in the United States and the residents of the Trobriand Islands, New Guinea, the genetic bond is associated only with mothers. ${ }^{95}$ The father is not viewed as having a direct connection with the child's conception, and the father-child relationship is established only as a matter of marriage, rather than as a matter of biology. And, in fact, also within Western culture, parenthood, and particularly fatherhood, was never a natural certainty but a legal fiction to ensure inheritance and lineage rights. ${ }^{96}$

The presumption of genetic tie as creating an intrinsic sense of attachment is also not grounded in reality. Numerous children around the world are abandoned each year by one or both of their genetic parents, whether in hospital maternity wards or later on. In some instances, children are deserted in a careless way, without a notice, or thrown into the garbage bin. The adoption of so-called "Safe Haven laws" in various countries, such as France and Germany, and many states in the United States are illustrative of this phenomenon: parents may relinquish

92 Ravitsky, Knowing Where You Come From, supra note 39, at 677-79.

93 Dorothy E. Roberts, The Genetic Tie, 62 U. CHI. L. REv. 209, 232 (1995).

94 KAHN, REPRODUCING JEWS, supra note 45, at 105.

95 Cohen, The Right Not to Be a Genetic Parent?, supra note 89, at 1140-41.

96 Ellen Waldman, The Parent Trap: Uncovering the Myth of "Coerced Parenthood" in Frozen Embryo Disputes, 53 AM. U. L. REV. 1021, 1028 (2004). 
unwanted newborns in certain designated areas or authorities, and they may do so without leaving any identifying information. ${ }^{97}$ The presence of a genetic link as an indication of attachment has also been repeatedly challenged in the case of gamete donors. Studies show that gamete donors, particularly sperm donors, are largely unconcerned with the offspring created from their gametes, have no sense of attachment to the potential offspring, and do not want to meet them in the future. ${ }^{98}$ Additionally, the rationales for gamete donation are often far removed from any desire to create an attachment. Donors, particularly men, are often motivated by financial interest, and some view their donations as not so different from blood donation. ${ }^{99}$

Nor is it clear that children give the same weight to genetic ties as do adults. Research shows that for children's sense of familial attachment, genetics is not paramount; rather, it includes household members, pets, a range of relatives, and individuals from other households. ${ }^{100}$ Studies of children born as a result of ART to same-sex family structures further reinforce the finding of children's nongenetic sense of kinship. Indeed, for these children, parentage is determined not so much by biological connection but by the way they were raised, and especially, the fact that they were planned and wanted all along. ${ }^{101}$

97 See, e.g., Ana L. Partida, The Case for "Safe Haven" Laws: Choosing the Lesser of Two Evils in a Disposable Society, 28 NEw ENG. J. ON CRIM. \& CIV. Confinement Vol. 61 (2002); Carol Sanger, Infant Safe Haven Laws: Legislating in the Culture of Life, 106 COLUM. L. REV. 753 (2006).

98 Waldman, supra note 96 , at 1049-52.

99 Id. at 1050 . Further note that, if the genetic tie is indeed so intrinsic in creating kinship relationship and merits its classification as a right, it is hard to see why donors who want to receive information about their related donor-conceived-children and even contact them should be prevented from doing so; it should further be questioned whether the power of gamete donors to simply waive such an intrinsic right is acceptable at all.

100 Jennifer Mason \& Becky Tipper, Being Related: How Children Define and Create Kinship, 15 CHILDHOOD 453-56 (2008).

101 Dena Moyal, \& Carolyn Shelley, Future Child's Rights in New Reproductive Technology: Thinking Outside the Tube and Maintaining 
Within the limited given data regarding sperm donation, studies show inconclusive results. Children younger than four years old in heterosexual families in Sweden questioned how they were born but reacted neutrally or not at all to the issue of gamete donation. ${ }^{102}$ In another study, over half of children between seven and seventeen years old who were raised by lesbian couples in Belgium preferred donor anonymity and roughly $20 \%$ were satisfied with nonidentifying information, such as physical appearance and personality. Sixty-three percent of these children also expressed no need in having conversations with their mothers about the donor. ${ }^{103}$ Moreover, differences were found also among donor-conceived children raised in the same family, including siblings from the same donor, leading the researchers to conclude that the donor-conceived child's interest in learning about his or her genetic origin is an individual matter. ${ }^{104}$ Conversely, in a study in Australia, most adolescents from the general population, including unknown donor-conceived children among them, who were surveyed about their opinion about donor parentage acknowledged the significance of the genetic

the Connections, 48 FAM. CT. REV. 431, 433 (2010); Susan Golombok et al., Families Created by the New Reproductive Technologies: Quality of Parenting and Social and Emotional Development of Children, 66 CHILD DEv. 285, 297 (1995); Zaira Papaligoura \& Colwyn Trevarthen, MotherInfant Communication Can Be Enhanced After Conception by In-Vitro Fertilization, 22 INFANT MENTAL HEALTH J. 591 (2001); José Gabilondo, Heterosexuality as a Prenatal Social Problem: Why Parents and Courts Have a Taste for Heterosexuality, in BABY MARKETS: MONEY \& THE NEW POLITICS OF CREATING FAMILIES 118, 124, 129, n.43 (Michele Bratcher Goodwin ed., 2010).

102 Sara Leeb-Lundberg et al., Helping Parents to Tell their Children about the $U_{\text {se }}$ of Donor Insemination (DI) and Determining Their Opinions about Open-Identity Sperm Donors, 85 ACTA OBSTETRICIA ET GYNECOLOGICA SCANDINAVICA 78, 79 (2006).

103 K. Vanfranssen et al., An Attempt to Reconstruct Children's Donor Concept: A Comparison between Children's and Lesbian Parents' Attitudes Towards Donor Anonymity, 16 HuM. REPRoD. 2019, 2021 (2001).

104 Id. 
connection to the donor but still identified the legal father as the parent. ${ }^{105}$

The degree to which these studies can be extended to donor-conceived children in the United States is unclear. The societal fabrics in all of these countries vary dramatically, and, generally, the above-mentioned international studies contain no information about religious and ethnic affiliation. Studies in the United States are prone to bias: current studies commonly revolve around donor-conceived-adults-hence after the process of enculturation which endorses the importance of genetics to kinship - and relied heavily on online listserves established especially by donor-conceived families with nontraditional family structure, i.e. single mothers and same-sex couples, to connect and communicate among themselves. ${ }^{106}$ Without an appropriate mechanism to trace the births of donorconceived children in the United States, future studies will inevitably be biased as well. Additionally, no studies appear to have examined whether the importance attributed to the genetic tie by the donor-conceived child differs depending on sperm and egg donation, particularly when the mother carried the pregnancy. American children's views about the significance of a genetic link should thus be further studied if we are to achieve a more accurate understanding of the consequences of disclosure in the United States.

\section{Medical Data}

Finally, a principal argument raised by disclosure proponents is that knowing one's genetic origins is important for medical reasons. This issue often arises when donor-conceived children are in the process of or have been diagnosed with disorders that have or are thought to have

105 Maggie Kirkman et al., Families Working it Out: Adolescents' Views on Communicating about Donor-Assisted Conception, 22 HuM. REPROD. 2318 (2007).

106 See, e.g., Our History and Mission, DonOR Sibling REGISTRY, https://www.donorsiblingregistry.com/about-dsr/history-and-mission/ (last visited Nov. 16, 2013). 
genetic links. 107 Disclosure of medical data is thus called for "in order to be aware of health risks, be able to take preventative measures, and have better ability to diagnose conditions as they emerge."108

Disclosure proponents raise two other related arguments. The first concerns unwitting incest relations of donor-conceived children with half-siblings. This argument is particularly pertinent in the United States. Unlike in other countries, there are no national- or state-level records on the birth of donor-conceived children or limits on the number of families that can receive donations from the same donor as exists for instance in France, Belgium, and the United Kingdom. Popular donors can thus father multiple children $-n$ one reported case, sperm from one donor resulted in sixty-four children.109 Incestuous relationships are socially unacceptable, and important for this discussion, they also increase the risk of genetic disorders if the siblings procreate. ${ }^{110}$ The second related argument underscores the issue of reproductive choice: the availability of the donor's medical data may influence the parental decision of whether to use the gamete of the particular donor, not to mention donor-conceived children's own reproductive decisions later in life. ${ }^{111}$

A requirement for disclosure of gamete donors' medical information is the strongest among the arguments considered so far. This is not to say that the argument is without a hitch. On the contrary, there are some serious difficulties with the implied suggestion that the importance

107 Ravitsky, Knowing Where You Come From, supra note 39, at 671-74; Vardit Ravitsky, Conceived and Deceived, 42 HASTINGS CTR. REP. 19 (2012); Rosas, supra note 32, at 395-96.

108 Ravitsky, Knowing Where You Come From, supra note 39, at 671.

109 Donor UnKNown: Adventures In THE SPERM Trade (Met Film and Redbird 2010).

110 In many states in the United States and elsewhere (e.g., Australia and the United Kingdom) incest relations also constitute a criminal offense. Naomi Cahn, Accidental Incest: Drawing the Line Or the Curtail? - For Reproductive Technology, 32 HARV. J.L. \& GENDER $59,85-89$ (2009).

111 Ravitsky, Knowing Where You Come From, supra note 39, at 672. 
of genetic origins for medical reasons is universal and with proponents' effort to frame access to donor's medical information as a right, rather than simply as a legitimate interest. Nevertheless, the argument holds true, especially given existing deficiencies in medical practice that prevent the appropriate and timely diagnosis of donor-conceived children who experience health-related symptoms that may be connected with genetic disorders. The following discussion thus aims to consider both the legal and ethical difficulties arising from the argument on the importance of medical data, ultimately concluding that the benefits of providing donor-conceived children access to such information do, in fact, outweigh the privacy concerns of gamete donors and recipient parents and justify the regulation of the work of fertility clinics in the United States.

The relevance of the donor's medical information is certainly of interest for a donor-conceived child who experiences health symptoms and is in the process of a medical diagnosis. This interest can be reasonably extended to other potential recipients and future donorconceived children who may develop the health condition if the same donor is used or who are concerned about the possibility of unintentional incest with half-siblings and the subsequent increased risk of genetic disorders. Demanding that gamete banks and fertility clinics perform due diligence in checking potential donors and establishing clear medical screenings of potential donors and guidelines to prevent donors diagnosed with genetic disorders from future donations are thus justified, as is limiting the number of families who use gametes from one donor so that the potential number of children born with genetic disorder that can be traced to the donor is reduced. Yet the argument related to the importance of the donor's medical data is more complex than it initially appears.

First, contrary to what disclosure proponents commonly imply, establishing causation between a health condition and inherited genetic disorders is not straightforward. Many genetic disorders occur as a result of spontaneous mutations that cannot be attributed to the genetic 
parents 112 or involve complex groups of genes not yet identified (e.g., autism). Simultaneously, it is generally agreed upon that human diseases have both genetic and environmental components to them, and that the interaction between these components is not fully known. ${ }^{113}$ The clinical usefulness of genetic testing may also be lacking. As Klitzman denotes, diagnosis does not always translate into an effective treatment, yet patients commonly believe that it does even when told otherwise ("diagnostic misconception").114 Concurrently, existing technologies in the fields of genetics and genetic counseling are often sufficient to diagnose donor-conceived children with known genetic mutations, to determine consanguine relationships, and to avoid the transmission of the more common disorders to the next generation through pre-implantation genetic diagnosis. Thus, the donor-conceived child's access to a donor's medical, and especially genetic, information is not inherently necessary for diagnosis, nor can it necessarily provide the panacea for all ailments that donor-conceived children may experience.

Second, it is problematic and erroneous to generalize from cases where a donor-conceived child experiences health symptoms and is in the process of obtaining a medical diagnosis that all donor-conceived children, including especially asymptomatic ones, have a general right to access the donor's medical and genetic data. Children do not normally have a right to access the medical and genetic information of their parents. ${ }^{115}$ They may request it when they are sufficiently mature and parents may choose to provide it, but this is not obligatory; indeed, medical secrets are often among the most guarded ones within families. ${ }^{116}$ Classifying it as a right, however, creates donors' direct

112 Rosas, supra note 32 , at 412 n. 172 .

113 Mark A. Rothstein, GINA, the ADA, and Genetic Discrimination in Employment, 35 J.L. MED. \& ETHICS 756, 838-39 (2008).

114 ROBERT L. KLITZMAN, AM I MY GENES? 40 (2012).

115 See discussion supra (discussing physician's duty of confidentiality to patients and to other relevant third-party beneficiaries).

116 See also KLITZMAN, supra note 114 , at 75-116 (discussing disclosure of genetic disorders in families). 
duty towards the donor-conceived child to reveal genetic disorders that run in the family or to be tested for genetic disorders. Such a proposition raises a few complexities. Donors, like other genetic parents, often do not know the details of their genetic makeup, 117 especially with regard to rare genetic disorders that are recessive or with conditions that occur in adulthood (e.g., Huntington's Disease). Concurrently, not everyone wants to know such information beforehand. It depends on personality, family and social circumstances, and, particularly in the United States, fear of discrimination in regard to employment or finding health and life insurance. ${ }^{118}$ Indeed, discrimination on the basis of one's genetic composition is a real possibility, despite the passage of GINA.119 If access to the donor's medical and genetic data is thus framed as a right with parallel obligations on gamete donors to be tested, donors are worse off than traditional parents, and donor-conceived children are granted a power that naturally-conceived children do not have. That is, unless under this emerging universal "child's right to know," similar requirements of disclosure of medical and genetic data will be imposed on all parents and families.

The construction of access to donors' and other genetic parents' medical and genetic information as a right further raises complicated questions of parental liability for genetic disorders that are hard-and, possibly, also socially wrong-to resolve. Existing legal regulations absolve the genetic parents from responsibility towards the child. These regulations were crafted to protect the privacy of both gamete donors and donor-conceived-families once donation and conception, respectively, were accomplished. Changing

117 A distinction in this context between genetic disorders and infectious diseases is in place. With regard to genetic disorders, there are some real questions as to the extent to which one knows about them for reasons I describe above; with regards to infectious diseases such as HIV/AIDS, on the other hand, there is greater room for expectation that one who was engaged in unsafe sex, drug use, etc "should have known" about the disease.

118 KLITZMAN, supra note 114 , at 37-47.

119 Anya Prince, Genetic Testing: $A$ New Civil Rights Frontier, Ability Magazine, Oct.-Nov. 2012, at 56-57. 
these regulations to allow for gamete donor liability because of genetic disorders, and regardless of the donor's knowledge thereof, ${ }^{120}$ would shatter this delicate balance. The notion of a right suggests a corresponding duty on the donor that raises the risk that gamete donors and, subsequently, all other parents will be seen as liable for any genetic disorders they may pass along to the child. In return, this opens the possibility that both naturally and donor-conceived children can make legal claims against their parents. Under such claims, the duty of the medical profession to beneficence and non-maleficence is extended to parents. ${ }^{121}$ It suggests that parents have a duty to prevent harmful conditions in their child, including a predisposition to genetic disease, and that children born with genetic disorders can file suit against their parents for failing to fulfill this duty. While courts have so far generally refrained from accepting such cases, demanding liability from gamete donors may give these claims new impetus.

Some scholars have addressed this issue as a philosophical matter. Jeffrey P. Kahn, for instance, argues that the general principle of "do no harm" obligates parents to prevent harmful conditions in their child, including a predisposition to genetic diseases that would bring about the child's suffering either at birth or later on in life. ${ }^{122}$ Others suggest that parents can -and have a moral duty to -choose a child without a disability as long as this choice does not risk them not having a child at all. ${ }^{123}$ Still others

120 If the donor purposefully conceals a known genetic disorder, liability may be in place - not as a matter of parental duty, however, but because of signing a donation contract not in good faith. See also Your Legal Responsibilities as a Sperm, Egg, or Embryo Donor, HuMAN FERTILISATION AND EMBRYOLOGY AUTHORITY, http://www.hfea.gov.uk/ 1972.html\#7204 (last updated Aug. 8, 2012) (stating that under U.K. law, donor-conceived children can sue donors for knowingly concealing a genetic disorder from the fertility clinic). And in California, it is a felony for a person who knows he has HIV or AIDS to donate sperm. Pi, supra note 32 , at 384 .

121 SABATELLO, CHILDREN's BIOETHICS, supra note 83, at 235.

122 Jeffrey P. Kahn, Genetic Harm: Bitten by the Body that Keeps You?, 5 BIOETHICS 289, 303-06 (1991).

123 Richard J. Hull, Cheap Listening? - Reflections on the Concept of Wrongful Disability, 20 BIOETHICS 55, 59 (2006). 
resort to the so-called "Non-Identity Problem" to dismiss the notion of liability on the basis of the child's disability. This argument suggests, "As long as the parental intervention does not produce a child whose 'life is not worth living,' we cannot say the child has been harmed (i.e., that this child is worse off) because a disabled life is better than no life at all."124

This is not a mere philosophical debate, however. On the one hand, to suggest that a child who was harmed will have no legal recourse because he or she would not have otherwise existed not only sets very low the standard of harm, ${ }^{125}$ but it also seems dismissive of the existing children who believe they were harmed. On the other hand, the suggestion that any arguable parental moral obligation can and should be translated into the child's legal right needs to be taken with caution. Disability is a natural phenomenon; it is part and parcel of human fabric, and, in fact, notwithstanding the sensational media reports, there is no study showing that the rate of donor-conceived children with disabilities is any higher than it is in the general population nor is it at all clear how many instances of unknown incest relations following gamete donation actually materialized into a child with disabilities. Creating a child's right to be "disability free" is therefore problematic not only as a matter of fact but also on social grounds. It looks at procreation merely as a matter of individual rights parental or child but ignores the interdependency among bearer of rights, especially in the context of reproduction and family relations. It lays down unreasonable expectations for parents, whose decision to procreate or to abort the fetus should be a personal choice. It also sends the wrong message that life with disabilities is not worth living, and it is likely to exacerbate, rather than reduce, the

124 I. Glenn Cohen, Intentional Diminishment, the Non-Identity Problem, and Legal Liability, 60 HAsTings L.J. 347 (2008); See also in the context of gamete donor's anonymity, Cohen, Rethinking SpermDonor Anonymity, supra note 20, at 435.

$125 \mathrm{Kim}$ M. Mutcherson, In Defense of Future Children: A Response to Cohen's Beyond Best Interests, 96 MINN. L. REV. HEADNOTES 55-56 (2012). 
already rampant discrimination against persons with disabilities.

The situation differs when gamete banks and fertility clinics are held liable for any genetic disorders passed along by donors. As the mediators between recipient parents and donors whose business and main interest is profit, gamete banks and fertility clinics are responsible for ensuring that the product that they provide is safe, regardless of whether gamete donation should be viewed as commodity. Certainly, caution is needed in this context as well. As many of the tests for various genetic disorders were only recently developed, it is very possible that these diagnostic capabilities were not available at the time of donation. Further, it is too demanding to require gamete banks to screen all samples for every possible genetic disorder. ${ }^{126}$ Indeed, conventional genetic parents who choose to receive genetic counseling are tested only for the most common genetic disorders that may occur given their ethnic background and not for all possible rare disorders.

Even so, the option of stipulating clear legal requirements from fertility clinics is more responsive to the interests of all stakeholders. As the go-between for gamete donors, recipient parents, and, later on, the donor-conceived child, fertility clinics are in a position to both meet the interest of donor-conceived children to access the medical information about the donor while still upholding the donor's interest of privacy. In fact, this was also the solution provided in the case of Johnson v. Superior Court of Los Angeles County in 2000, where a child conceived with donated sperm was diagnosed with a severe kidney disease called Autosomal Dominant Polycystic Kidney Disease ("ADPKD") that was traced back to the donor. ${ }^{127}$

126 Rosas, supra note 32 , at 413.

127 Johnson v. Super. Ct., 95 Cal. Rptr. 2d 864 (App. 2000). In this case, the recipient parents along with their minor daughter brought fraud causes of action against Cryobank and others alleging that they failed to disclose that the sperm donation they sold to them came from a donor with a history of this kidney disease. The question presented to the court was whether the plaintiffs can compel the donor's deposition and production of documents in order to discover information relevant to their action against Cryobank. 
Recognizing the legitimate privacy interests of the sperm donor, the court ruled that while the fertility clinic, California Cryobank, Inc., ("Cryobank") has to provide the medical data relevant to the case at stake, the donor's "identity is to be protected to the fullest extent possible and the identities of his family members are not to be disclosed." Put differently, there is no reason why a separation between the responsibility of fertility clinics to record, preserve, and provide medical data about the donor, including follow up with donors when necessary, and the anonymity of the donor in respect with the recipient parents and the donorconceived child cannot be clearly established in law. In this way both the privacy interest of the gamete donor and the interest, but not right, of donor-conceived children in accessing the donor's medical information are being upheld; the legal requirement of disclosure merely preventing fertility clinics - the only party who is in this field for the purpose of financial profit-from hiding behind the veil of donors' anonymity for their financial gain.

The shift towards the responsibility of gamete banks and fertility clinics-and the subsequent need to regulate access to the medical information of gamete donors' in the United States-is further strengthened when more systematic deficiencies in medical practice in the United States are considered. Specifically, two such deficiencies should be mentioned.

The first is that although genetic counseling and existing technologies in the field of genetics are often sufficient to diagnose donor-conceived children with known genetic disorders, to determine consanguine relationships, and to avoid the transmission of a disorder to the next generation through pre-implantation genetic diagnosis on the basis on one's genetic composition alone, such diagnoses are often missed. This is especially so with regard to rare genetic diseases, as primary healthcare providers often lack sufficient knowledge and awareness about the prognoses and testing of such diseases. ${ }^{128}$ This is true also for fertility clinics. Reports show that when they receive information 
about medical symptoms experienced by a donor-conceived child, they often fail to tie it to the donor and to take necessary steps to avoid the further use of the donor's gamete. ${ }^{129}$ This barrier is further exacerbated in the United States as its private healthcare system, unique among its Western counterparts, operates on referrals to specialists rather than on the appropriate training of primary care providers. Additionally, unlike other countries that provide national healthcare, the private insurance companies in the United States may refuse to cover the associated costs of this testing, and, indeed, they do so commonly. ${ }^{130}$ Even though many of these insurance decisions are eventually reversed upon appeal, ${ }^{131}$ much time and money is wasted before the donor-conceived child is diagnosed and treated. It is also for this reason that developments in "personalized medicine," where the "one size fits all" model of medical treatment shifts towards one that "tailors prediction, diagnosis and treatment to the individual,"132 may not necessary yield any better results. This form of medicine still requires highly qualified physicians who are invested in the individual and receptive insurance companies who will cover the bills.

Second, in the United States, the effort to receive a genetic diagnosis that can be traced to the gamete donor is in many ways tied with the question of fertility clinics' accountability. As the gate-keepers of information about gamete donors, fertility clinics who failed to properly follow up on information about genetic disorders or other medical conditions of the donor and his or her family can, and have, argued that donors' anonymity prevents them from

129 See Ayesha Ahmad, Danish Sperm Donation Law Tightened After Donor Passes on Rare Genetic Disease, BIoNews (Oct. 1, 2012), http://www.bionews.org.uk/page_186023.asp; Rosas, supra note 32, at 394-96.

130 KLITZMAN, supra note 114 , at 34-37.

131 UNITED STATES GOVERNMENT ACCOUNTABILITY OFFICE, No. GAO-11-68, PRIVATE HEALTH INSURANCE: DATA ON APPLICATION AND COVERAGE DENIALS 16-26 (2011), available at http://www.gao.gov/new. items/d11268.pdf.

132 Richard Tutton, Personalizing Medicine: Futures Present and Past, 75 SOC. SCI. \& MED. 1721 (2012). 
providing such information to recipient parents. The ability of fertility clinics to evade responsibility is further exacerbated by the lack of comprehensive requirements to preserve the medical information of the gamete donor or to enable follow up with donors who may have passed along genetic disorders. They may simply argue that this information is no longer available. In the lack of national single-payer healthcare or a no-fault system for compensation for medical injuries as exist, for instance, in various Scandinavian countries such as Sweden, individuals are more likely to sue clinics for negligence to recover the mounting costs. Indeed, in the only case in the United States revolving around disclosure of gamete donation for medical reasons, the issue at stake was the fertility clinic's effort to conceal its knowledge about the donor's genetic disorder during the subsequent medical malpractice suit. ${ }^{133}$

These deficiencies in medical practice will not disappear under the Patient Protection and Affordable Care Act ("ACA").134 The ACA extends the group of persons eligible to apply for healthcare insurance including especially those with pre-existing conditions and creates more incentives for insurances to cover the uninsured through the so-called exchange program that requires coverage of essential health benefits to be determined by the government. It does not,

133 Johnson v. Super. Ct., 95 Cal. Rptr. 2d 864 (App. 2000). Disturbingly in this case, however, the Superior Court of Los Angeles County ultimately denied the request of the recipient parents and the donor-conceived child that she is entitled to recover general damages or damages for lost earnings. The court stated, "Regardless of what petitioners allege with respect to causation, it cannot be said that Cryobank, Sims and Rothman caused Brittany's [the child] inherited abnormalities by improperly approving Donor No. 276 as a sperm donor. Brittany's kidney condition was caused by the gene contained within the sperm provided by Donor No. 276." The court thus determined that this request was justly classified by the trial court as a wrongful life case, and that its decision was bound by the decision of the California Supreme Court in Turpin v. Sortini, 643 P.2d 954 (Cal. 1982) (denying entitlement to recover general damages or damages for lost earnings for a child who was born deaf due to medical malpractice).

134 Patient Protection and Affordable Care Act, Pub. L. No. 111-148, 124 Stat. 119 (2010) (codified as amended in scattered sections of 21, 25, 26,29 , and 42 U.S.C.). 
however, change the process of insurance decision-making about which treatments are considered medical necessitya threshold for coverage also within the range of those essential health benefits-hence potentially leaving the number of denial of benefits unchanged. The ACA also does not change the fault-based, adversarial system that exists in the United States, and, overall, it is unlikely to reform the system of delivering healthcare services in the United States so that it resembles the situation in other countries that provide national healthcare to all.

Establishing clear medical screenings of potential donors; requiring due diligence from fertility clinics; reexamining existing samples for genetic disorders; follow up with gamete donors to see if they develop disease later when there is an indication, in light of the medical condition of the donor-conceived-child, for possible genetic disorder; and similar measures are thus justified to rectify deficiencies in medical practice, especially in the United States, that significantly impact donor-conceived children. This remains the case even though the number of donorconceived children who are born with genetic disorders, or disabilities generally, is unknown, as is whether this figure exceeds the rate of children born with genetic disorders and disabilities in the general population. As the medical profession and fertility clinics have failed to properly address this issue on their own, the government's use of its parens patria powers is thus grounded in the protection of donor-conceived children who had no say about whether or not they will be born.

To be sure, regulating how gamete banks and fertility clinics handle donated gametes will not solve all the dilemmas that arise. One such complex issue is the question of disclosure of genetic disorders. For instance, it is questionable whether young donor-conceived children (as other children-and in fact, also adults) want and can cope with information about one's genetic composition, particularly if they are asymptomatic and given the possible negative repercussions if genetic disorders are diagnosed. The scope of the duty to disclose the donor's genetic disorder is also not as straightforward as it may seem. For instance, 
if a donor-conceived child is diagnosed with a genetic disorder that can be attributed to the donor, should gamete banks and fertility clinics contact all donor-conceived children from that donor, including asymptomatic ones, to inform them about the disorder? Moreover, the extent to which it is possible to protect donor-conceived children in particular from being unintentionally forced to face disclosure of their potential genetic disorders should be considered. With the rise of Internet communication, recipient parents or donor-conceived children may post information on online listserves for donor-conceived families about the diagnosis of genetic disorders, thus in effect informing other recipient parents and donor-conceived siblings whom they have never met or have met merely through the online forum about their own possible genetic composition. This is troubling given that the meaning of such information may be unclear and inaccurate, especially if provided by people who are not experts in the field, and, moreover, it is also potentially emotionally devastating. Studies on these questions are essential to determine the ethical and legal standards that should apply.

What this discussion illustrates is that the distinction between the goal of a donor's medical surveillance and the child's right to know needs to be clarified. As a matter of public health policy, the collection of the donor's medical data is critical. The donor chose to donate gametes; the subsequent collection of medical information, therefore, cannot be regarded as too invasive to his or her right to privacy. As fertility clinics are the most direct mediators of the interests of the various stakeholders in this process, regulating their work is within the legitimate scope of the governmental use power. As the prime bodies who are in the business of making babies and money, they should be held to higher standards of due diligence in their work. Yet, the importance of the collection of medical information and its disclosure cannot, and should not, be automatically translated into a right of donor-conceived children to demand that other identifying information be provided to them. Access to medical information as an interest should be separated from a discussion about rights, where a true 
balancing between the arguable rights of recipient parents, gamete donors and donor-conceived-children is practically impossible.

\section{CONCLUSION}

My challenges to disclosure proponents' arguments do not intend to deny that donor-conceived children have an interest in accessing information relating to their donors or to dismiss the frustration they feel when such information is unavailable to them. It is also not intended to endorse family secrets especially in the context of health and reproduction as a preferable option. Rather, my criticism lies in the implied universality of proponents' claims, particularly given that only limited data exist and almost none of that which pertains to the United States. Moreover, classifying disclosure of one's circumstances of conception and of gamete donor's information as a right is problematic. Not every interest one has-as valuable as it may be-can or should be translated into a right. A right should have a moral foundation; it should be universally applicable and empowering, its exercise free from complete control of others.

Current discussions of the context of disclosure of gamete donation and the child's right to know do not follow these requirements. In short, an interest in a donor's medical and genetic data does not necessarily extend to the provision of other identifying information; it also raises serious questions about the scope of genetic screening, healthcare insurance, and other relevant responsibilities associated with disclosure. As discussed, the claim that all donor-conceived children share a similar interest in disclosure is dubious; it is moreover unclear what role the donor-conceived family structure plays in this interest. Religious and other cultural considerations also play pivotal roles in parental decisions to disclose the circumstances of conception to their children, and ignoring these considerations may lead to serious social consequences for all involved. The broader implications of a universal right to know requires balancing the interests of donor-conceived 
children, donors, and recipient parents; additional debate and study of the role of the state; and clearer understanding of the interplay between law, multiculturalism, Western liberalism, and truth-telling in family relations.

Whether donor-conceived children want to know, if it is in their best interest, and who decides are all critical questions. Clearly, further research is needed. The views of donor-conceived children from various familial, ethnic, and religious backgrounds, including, in particular, donorconceived children who do not know, are crucial. This is especially the case with data based in the United States, which, ironically, can only be collected and improved if the field is regulated. Given the United State's private healthcare system, preference for non-interventionist governance and predilection for a free market, the implications of disclosure differ significantly from those in other countries that reversed the policy of donors' anonymity. All of these issues need to be carefully considered if viable policies are to be achieved.

Conceptualizing access to information about one's genetic origin as a right is also erroneous. It positions disclosure as the primary, possibly sole, factor necessary for donor-conceived children and families to prosper and thrive. In no other context is truth-telling granted such absolute power without proper, unbiased studies that justify interference. Stipulating a right to know one's genetic sources that is entirely dependent on others for its implementation is insufficient, and adopting measures to ensure one's ability to independently exercise it is essential. Moreover, if disclosure is paramount-indeed, a right-it should extend to all children who do not know their story of conception or the identities of their parents. As measures akin to an active registry and imposed genetic testing at birth-measures that undoubtedly stand in stark contrast with the United States principle of privacy and noninterference approach-are not likely to find many supporters, setting appropriate regulations on the work of fertility clinics in performing reproduction through gamete donation would yield better results. 
Gamete donation regulations that focus on fertility banks and clinics can address the most urgent need in this field, that is: the protection and assistance to donorconceived children who are diagnosed or in the process of being diagnosed with genetic disorders. Such regulations should require fertility banks and clinics to establish clear medical screenings of potential donors and to record appropriate information about gamete donors so as to allow also for follow-ups and the reexamination of samples for genetic disorders when there is indication for a possible genetic disorder Such regulations would also respond to deficiencies in medical practice, which are exacerbated in the United States where the private healthcare system and the need to resort to courts are both unique. Simultaneously, allowing the parents the choice of whether to disclose the gamete donation or to keep it a secret is in line with the United States' social and cultural traditions of familial privacy. This is the case even though encouragement of parental disclosure may be promoted (but not imposed).

The aforementioned discussion and the recommendations for gamete donation regulations for medical purposes are not set in stone. As a social phenomenon, the field of gamete donation is continuously developing, and in the future, other adjustments and changes might be in place. With the possibility of follow up, fertility clinics and banks might find that donors are not as averse to disclosure of their non-identifying and even identifying information as historically been the case. The availability of information about gamete donors might play a role in the recipient parents' decision to disclose the gamete donation to the donor-conceived child. The availability of such information might additionally reduce the anxiety of some donor-conceived children who know about their circumstances of conception-even if they choose not to access it. Then again, another possible development might be that the more society accepts nontraditional, social and non-genetic families and moves towards personalized medicine, the less appealing information about gamete donors would be for donor- 
conceived children who, in actuality, might have very little in common with the gamete donor. Indeed, ultimately, the solution for complexities arising in the context of gamete donation should be tailored to the needs of specific societies and responsive to the interests of all stakeholders involved. 
